\title{
Vigilância jurídica em saúde: A centralidade do direito sanitário para a materialização do direito constitucional à saúde
}

\author{
Legal surveillance in health: The centrality of health law for the materialization of the \\ constitutional right to health
}

Vigilancia jurídica en salud: La centralidad del derecho sanitario para la materialización del derecho constitucional a la salud

Recebido: 26/04/2021 | Revisado: 04/05/2021 | Aceito: 08/05/2021 | Publicado: 23/05/2021

\author{
Dorival Fagundes Cotrim Junior \\ ORCID: https://orcid.org/0000-0002-7389-7635 \\ Instituto de Medicina Social Hésio Cordeiro, Brasil \\ Pontifícia Universidade Católica do Rio de Janeiro, Brasil \\ E-mail: dorivalfcotrim@gmail.com \\ João Paulo Almeida Brito da Silva \\ ORCID: https://orcid.org/0000-0001-9750-7569 \\ Instituto de Medicina Social Hésio Cordeiro, Brasil \\ Fundação Oswaldo Cruz Brasília, Brasil \\ E-mail: jp.brito.bsb@gmail.com
}

\begin{abstract}
Resumo
O artigo, construído a partir de uma metodologia exploratória, investiga a possível centralidade do direito sanitário para a materialização do direito constitucional à saúde. Inicialmente delimita-se o direito sanitário, compreendido como direito coletivo e formador de um campo jurídico autônomo, com ênfase na vigilância sanitária, dado o seu caráter de redução de riscos, doenças e agravos. Por isso analisou-se duas leis infraconstitucionais, a Lei Orgânica da Saúde e a Lei da Vigilância Sanitária, para conceituar esse termo; e a Constituição Federal de 1988, a fim de identificar as competências administrativas e legislativas em saúde pública e especificamente em vigilância sanitária. $\mathrm{O}$ resultado encontrado é que o Estado só conseguirá cumprir o seu dever constitucional quando estiver dotado de uma instrumentação jurídica sanitária robusta, capaz de materializar o direito à saúde nessa perspectiva pública.
\end{abstract}

Palavras-chave: Direito sanitário; SUS; Vigilância sanitária; Políticas de saúde.

\begin{abstract}
The article, built from an exploratory methodology, investigates the possible centrality of health law for the materialization of the constitutional right to health. Initially, it delimits the health right, understood as a collective right and forming an autonomous legal field, with emphasis on health surveillance, given its character of reducing risks, diseases and illnesses. Therefore, two infra-constitutional laws were analyzed, the Organic Health Law and the Sanitary Surveillance Law, in order to conceptualize this term; and the Federal Constitution of 1988, in order to identify the administrative and legislative powers in public health and specifically in sanitary surveillance. The result found is that the State will only be able to fulfill its constitutional duty when it is equipped with a robust legal instrumentation sanitary, capable of materializing the right to health in this public perspective.
\end{abstract}

Keywords: Health law; SUS; Health surveillance; Health policies.

\section{Resumen}

El artículo, construido a partir de una metodología exploratoria, investiga la posible centralidad del derecho sanitario para la materialización del derecho constitucional a la salud. Inicialmente delimita el derecho a la salud, entendido como un derecho colectivo y formando un campo jurídico autónomo, con énfasis en la vigilancia de la salud, dado su carácter de reducción de riesgos, enfermedades y lesiones. Por lo tanto, se analizaron dos leyes infraconstitucionales, la Ley Orgánica de Salud y la Ley de Vigilancia Sanitaria, para conceptualizar este término; y la Constitución Federal de 1988, para identificar las competencias administrativas y legislativas en materia de salud pública y específicamente de vigilancia sanitaria. El resultado encontrado es que el Estado sólo podrá cumplir con su deber constitucional cuando se dote de una robusta instrumentación jurídica sanitaria, capaz de materializar el derecho a la salud en esta perspectiva pública.

Palabras clave: Derecho sanitario; SUS; Vigilancia sanitaria; Políticas sanitárias. 


\section{Introdução}

O presente trabalho objetiva analisar a vigilância jurídica em saúde, a fim de perceber se há, ou não, a centralidade do direito sanitário para a materialização do direito constitucional a saúde.

Para investigar teoricamente e comprovar ou não tal hipótese, primeiro buscou-se uma delimitação conceitual sobre o direito sanitário. Em seguida, este foi analisado a partir da ótica da vigilância em saúde, e assim perceber a sua importância para assegurar o dever constitucional de proteção à saúde. A fim de encorpar o sentido de vigilância em saúde, incorporou-se uma breve análise da Lei n. 9782/1999 e da Lei Orgânica da Saúde, explicitando as competências administrativas e legislativas de cada ente federativo a respeito da saúde pública em geral e da vigilância sanitária em específico.

\section{Metodologia}

A metodologia utilizada na pesquisa foi a exploratória (Gil, 2009), cujo objetivo é o de proporcionar uma maior familiaridade com o tema abordado, tornando-o mais explícito e possibilitando, em alguma medida, a construção de hipóteses. Por isso foi possível formular a hipótese do trabalho: o direito sanitário é central para a materialização do direito constitucional à saúde.

A pesquisa realizada é de natureza qualitativa e não quantitativa, além de fundamentalmente descritiva, uma das características da pesquisa exploratória. Como ainda não há uma sistematização robusta das informações e teorias, optou-se por este tipo de estudo. $\mathrm{O}$ artigo desencadeia investigações para identificação do fenômeno da centralidade do direito sanitário, apontando algumas das suas características qualitativas essenciais, vistas como necessárias à concretização do direito constitucional à saúde. Ou seja, cumpre o objetivo de uma pesquisa exploratória, qual seja, a descrição/caracterização da natureza das variáveis de um determinado fenômeno (objeto de pesquisa) que se quer conhecer (Köche, 2011).

\section{Resultados e Discussão}

\subsection{Delimitações iniciais sobre direito sanitário}

Conceituar o direito sanitário é uma tarefa deveras difícil, dada a pluralidade de usos nas mais diversas situações, o que não deixa de derivar, também mas não somente, da própria imprecisão conceitual do termo "saúde" (Scliar, 2007) (Almeida Filho \& Jucá, 2002), que não significa apenas ausência de doença como igualmente envolve o chamado "completo bem estar físico, mental e social” (S. G. Dallari, 1988). Vista em sua época como uma definição avançada, desde muito tempo já se tornou “irreal, ultrapassada e unilateral” (Donnangelo, 1976) (Segre \& Ferraz, 1997) (Batistella, 2007) (Luz, 2014).

Ainda assim é preciso buscar os variados conjuntos de normas concernentes ao tema da saúde, como regulação das profissões médicas, do ensino na área de saúde, da vigilância sanitária, do planejamento e política em saúde, entre outras para que seja possível operar alguma delimitação conceitual a respeito do direito sanitário (S. G. Dallari, 1988).

Percebe-se, portanto, o expressivo quantitativo de escritos legais a respeito do direito sanitário, acrescidos ainda, a partir dos séculos XIX e XX, quando o Estado assumiu a prestação dos cuidados de saúde na qualidade de serviços públicos. Nessa toada é mister fixar que toda atividade administrativa do Estado é realizada sob a primazia da lei (S. G. Dallari, 1988), isto é, em outros palavras, a Administração Pública está limitada pelos princípios do Direito Administrativo, como a o da Legalidade e da Supremacia do Interesse Público (Di Pietro, 2017). Assim, o Executivo busca realizar os objetivos definidos nos textos legais a partir dos meios aventados também na forma da lei, com algum grau de discricionariedade nesta execução.

É cediço o aspecto coletivo da saúde, muito além do individual, o que significa, para os fins do texto, a insuficiência de disponibilizar às pessoas os meios para "promoção, manutenção ou recuperação da saúde" para que o Estado cumpra razoavelmente a obrigação de garantir a saúde da população. Atualmente a maioria dos Estados são constitucionalmente forçados 
a tutelar a saúde contra praticamente todos os perigos (S. G. Dallari, 1988), resultando daí, também, o caráter coletivo da saúde pública/coletiva.

O trabalho da vigilância sanitária, materializada pela Agência Nacional de Vigilância Sanitária (ANVISA), é um exemplo de tal afirmação (Silva et al., 2018). E a Administração Pública, ainda que os governantes não queiram, devem cumprir e fazer cumprir as disposições legais.

Dallari (1988) ainda aponta que, especialmente na contemporaneidade, o nível de saúde de um determinado conjunto demográfico "depende do seu nível de desenvolvimento" social, econômico e cultural. Ou seja, não basta que haja serviços voltados à "promoção, proteção e recuperação sanitária adequados e em número suficiente, nem a existência de normas legais prevendo todas as hipóteses de agravos à saúde pública" sem que o Estado não tenha atingido níveis tais dos modos de desenvolvimento citados, uma vez que sem eles torna-se impossível gozar dos recursos técnicos existentes e necessários, atender as demandas de infraestrutura e dispor de uma população consciente dos seus direitos à saúde, isto é, "sanitariamente conscientes" (Berlinguer, 1978).

Como a saúde é igualmente dependente desses níveis de desenvolvimento e a sociedade juridiciza os rumos definidos para alcançá-los, as disposições legais, de observância obrigatória pela Administração Pública, estão ou devem estar nos planos de desenvolvimento do Estado.

Portanto, o direito da saúde pública não é somente parte do direito administrativo, como apontou Dallari (1988) até certo momento do texto, mas tem fortes implicações com esse ramo do direito pelo fato de costumeiramente referir-se a atuação estatais orientadas; e por conduzir-se pelos princípios elementares da supremacia do interesse público e da indisponibilidade do interesse público. Ou seja, não basta referir-se ao direito administrativo, pois peculiariza-se o direito da saúde pública.

Machado (2009) adverte que tradicionalmente a ideia de direito à saúde no Brasil tem se restringido a "uma concepção de acesso aos bens e serviços de saúde", mas que essa concepção não coaduna com a própria história de luta pela afirmação do direito à saúde como um direito de cidadania, conforme pautado pelos múltiplos atores dos Movimentos pela Reforma Sanitária (Escorel, 1999) (Jairnilson Silva Paim, 2008) (Cotrim Junior, 2019). Ou seja, não se trata apenas de prestação de determinados serviços à população.

A própria Carta Constitucional, uma das mais progressistas do mundo (Cittadino, 2002), preconiza a saúde como "direito de todos e dever do Estado" e o art. $3^{\circ}$ da Lei Orgânica da Saúde define os fatores determinantes da saúde, "a alimentação, a moradia, o saneamento básico, o meio ambiente, o trabalho, a renda, a educação, o transporte, o lazer e o acesso aos bens e serviços essenciais". Uma definição bem mais ampla que a de acesso aos serviços de saúde (Machado, 2009).

Pelo exposto, não obstante as referidas previsões, ainda há quem defenda o direito à saúde como um direito do consumidor, ou um dos pilares desse ramo jurídico, o que parece transformar o Sistema Único de Saúde (SUS) em um plano de saúde, o que não condiz com a proposta desenhada pelos movimentos da Reforma Sanitária. Se, por um lado, tratá-lo como direito do consumidor permite a requisição do acesso a bens e serviços de saúde na justiça, por outro afasta a saúde do rol dos direitos coletivos e difusos (não individualizados pelo mercado), reduzindo-o a intervenções pontuais e tornando impossível comportá-los sob a ótica dos determinantes da saúde, tal como previsto pela referida Lei Orgânica (Machado, 2009).

O direito sanitário, em nossa perspectiva, transcende um direito individual a bens específicos de saúde. Ainda que eles sejam importantes, no interior dessa concepção como algo individual implicitamente impera uma ideia de que, "como os recursos são invariavelmente escassos, ou seja, não estão disponíveis para o conjunto da sociedade, devem ser garantidos àqueles que o buscam". Dessa forma, o direito individual é garantido, ao mesmo tempo que se exclui outra parcela da população do usufruto deste direito (Machado, 2009).

O direito à saúde em perspectiva coletiva amplia o "escopo de reivindicações", uma vez que torna possível o exsurgir de novas necessidades e demandas. E uma possível "saída para o dilema da gestão dos recursos escassos pode estar no 
acirramento da construção de espaços efetivos de participação popular", que sejam partes integrantes da gestão em saúde (Machado, 2006), mas que não serão aqui abordadas (Machado, 2009). Tal busca por materialização de uma soberania popular pode ser também uma possível saída para a clássica contradição entre Estado e garantia de direitos no seio do capitalismo (Oliveira, 2020) (Garcia et al., 2020), sendo a comunicação um dos "determinantes políticos" centrais para a construção de uma base social de apoio ao direito à saúde (ao SUS), de práticas de soberania popular (Santos et al., 2021)

Enfim, o direito sanitário é um direito coletivo e que forma um campo "autônomo" do direito, como o Direito Civil, Penal, Processual etc. e assim deve ser estudado (Aith, 2006), sob pena de cair em reducionismos incapazes de apreender a complexidade em torno do direito à saúde.

\subsection{O direito sanitário sob a ótica da vigilância em saúde}

O direito sanitário, sob a ótica da vigilância em saúde, apresenta como alguns dos seus objetivos a busca pela redução dos riscos de doenças e outros agravos à saúde da população, o condicionamento e a proibição de condutas; assim como orientação da Administração Pública no sentido da adoção de medidas concretas para identificação de riscos à saúde que podem existir na sociedade; e para a adoção de medidas cabíveis capazes de evitar ou minimizar os riscos e danos potencialmente causados (Aith, 2019).

Não apenas as condutas humanas apresentam riscos à saúde individual, mas também inúmeras outras situações ditas "naturais", como o surgimento de um vírus. Entretanto, como a pandemia da COVID-19 explicitou (Watts et al., 2018) (Germain et al., 2019) (Manzanedo \& Manning, 2020) (Herrero \& Thornton, 2020), não devemos mais trabalhar com análises dualistas entre natureza e cultura, como algumas filosofias da Modernidade nos apresentam, mas numa perspectiva de simbiose, que entenda as duas dimensões como complementares, e em regime permanente de afetação, cujos exemplos atuais são a do francês Bruno Latour (Latour, 1991) e do brasileiro Eduardo Viveiros de Castro (Castro, 1992).

Além da saúde individualizada, temos outras possibilidades de riscos, que dizem respeito à saúde pública. São os casos de epidemias, pandemias, surtos, mas também a infecção hospitalar, a proliferação excessiva de um agente transmissor, entre outras (Aith, 2019) (Gomes \& Gonzaga e Castro, 2012). Para todas estas situações o Estado precisa responder de alguma forma, dado o dever constitucional de garantir a saúde da população, exatamente o que não está sendo feito em tempos pandêmicos da COVID-19 (Cotrim Junior et al., 2020) (Tavares et al., 2020) (Cotrim Junior et al., 2021) (Aith et al., 2020) (Cotrim Junior \& Cabral, 2020) (Ortega \& Orsini, 2020) (Santos, 2020).

\subsection{O dever constitucional de proteção a saúde e como assegurá-lo? A importância do direito sanitário}

Agora a pergunta que surge é a seguinte: como pode o Estado cumprir com o seu dever constitucional? É preciso municiá-lo de uma instrumentação jurídica robusta e eficaz, capaz de fornecer ao administrador público as ferramentas necessárias às ações concretas com vistas à redução ou anulação dos riscos à saúde (Buss et al., 2012) (L. Santos \& Andrade, 2012) (Fleury et al., 2011). Disto decorre a centralidade da discussão jurídica para a governança em saúde, que não prescinde de regramentos normativos.

Assim, no âmbito da vigilância em saúde a atividade do Estado adquire ou deve adquirir a forma de política pública permanente, contínua e incessante, orientada à identificação dos possíveis riscos sanitários e consequentemente à adoção das medidas concretas corretas o suficiente para evitar ou reduzir os riscos. Neste sentido, portanto, o agenciamento da Saúde com o Direito põe para este a tarefa de fornecer as bases jurídicas para que a Administração Pública crie, acompanhe e aperfeiçoe políticas sociais e econômicas voltas à redução de doenças e agravos em saúde, mas também, e não menos importante, para que a Administração seja capaz de estabelecer as condições assecuratórias do acesso universal, igualitário e gratuito às ações e serviços de saúde (Aith, 2019) (S. G. Dallari, 2002) (Jairnilson Silva Paim \& Silva, 2010) (Campos, 2006). 
É a partir do Direito Sanitário que o Estado organizará suas políticas públicas de saúde no sentido normatizado pela Carta Constitucional de 1988, ou seja, considerando a saúde como um dever do Estado e um direito dos cidadãos (Aith, 2006) (S. G. Dallari, 2002). Exemplificativo de tal diretriz é a Lei n. 9.782/1999, instituidora do Sistema Nacional de Vigilância Sanitária e criadora da Agência Nacional de Vigilância Sanitária (ANVISA), pois orientam a ação do Poder Público em direção à redução do risco de agravos e doenças, especialmente por "desempenhar papel fundamental no controle da produção, comercialização e consumo de produtos e insumos que afetam a saúde humana” (Baptista et al., 2009) (Costa, 2009).

\subsection{Materialização jurídica da vigilância em saúde: a Lei n. 9782/1999}

$\mathrm{O}$ art. 2, inciso I, determina que compete à União, no âmbito do Sistema Nacional de Vigilância Sanitária (SNVS), definir a política nacional de vigilância sanitária. Tal política é materializada em uma série de normas jurídicas que compõem o vasto acervo de regramentos do Direito Sanitário (Aith, 2019); e desde 12 de julho de 2018 o país finalmente instituiu a Política Nacional de Vigilância em Saúde, a partir da Resolução n. 588/2018 do Conselho Nacional de Saúde (CNS) (De Seta, 2007) (De Seta \& Dain, 2010) (Seta et al., 2017).

O artigo 7 estabelece e enumera as competências da ANVISA, dentre as quais destacamos o estabelecimento de "normas, propor, acompanhar e executar as políticas, as diretrizes e as ações de vigilância sanitária"; o dever de coordenador o Sistema Nacional de Vigilância em Saúde; e de fomentar e realizar estudos e pesquisas no seio das suas atribuições.

É destaque ainda a Lei n. 6.259/1975, cujo conteúdo “dispõe sobre a organização das ações de Vigilância Epidemiológica, sobre o Programa Nacional de Imunizações, estabelece normas relativas à notificação compulsória de doenças, e dá outras providências" (Temporão, 2003). Dentre as suas competências está a obrigatoriedade de "utilizar-se dos recursos a ela atribuídos pela legislação sanitária em vigor para a proteção da vida e da integridade física e mental da população", caso a autoridade se depare com hipóteses excepcionais de doenças e agravos que ameacem a saúde pública, conforme o art. 12 da Lei.

Com vistas à concretização do dever constitucional de proteção da saúde, especialmente no que tange à redução de riscos, doenças e agravos, o art. 13 da referida lei determina que as pessoas físicas e as entidades privadas devem sujeitar-se ao controle determinado pela autoridade sanitária (Aith, 2019).

É o art. 196 da Carta republicana de 1988 o determinante jurídico orientador da atuação e regulação do direito em saúde, não apenas os voltados à vigilância em saúde, pois assegura que a saúde é um direito de todos e um dever do Estado (Aith, 2019) (Aith, 2006), que deverá ser garantida pela criação, manutenção, aperfeiçoamento e execução de "políticas sociais e econômicas que visem a redução do risco de doenças e de outros agravos e ao acesso universal e igualitário às ações e serviços para sua promoção, proteção e recuperação" (Bonavides, 2019).

Com base em tais orientações que o direito sanitário regulamenta e determina a atuação da Administração Pública na criação, manutenção e execução de políticas públicas voltadas à efetivação do direito à saúde (Aith, 2019). A importância do Direito Sanitário cresce ainda mais quando se percebe a necessidade de busca incessante de condições para a materialização do acesso universal e igualitário às ações e serviços de proteção, recuperação e promoção da saúde, individual e coletiva.

\subsection{A imprescindibilidade da legislação infraconstitucional: o caso da lei orgânica da saúde}

A legislação infraconstitucional de Direito Sanitário especifica alguns conceitos importantes e relacionados às atividades de Vigilância, como é o caso da Lei Orgânica da Saúde (Lei n. 8.080/90), que em seu parágrafo $1^{\text {a }}$ do art. 6 apresenta uma conceituação jurídico-formal de vigilância sanitária, como

Um conjunto de ações capaz de eliminar, diminuir ou prevenir riscos à saúde e de intervir nos problemas sanitários decorrentes do meio ambiente, da produção e circulação de bens e da prestação de serviços de interesse da saúde, abrangendo: 
I - o controle de bens de consumo que, direta ou indiretamente, se relacionem com a saúde, compreendidas todas as etapas e processos, da produção ao consumo; e

II - o controle da prestação de serviços que se relacionam direta ou indiretamente com a saúde.

Quanto à vigilância epidemiológica, a mesma Lei Orgânica (LOS), art. 6, parágrafo 2 assim conceitua:

Entende-se por vigilância epidemiológica um conjunto de ações que proporcionam o conhecimento, a detecção ou prevenção de qualquer mudança nos fatores determinantes e condicionantes de saúde individual ou coletiva, com a finalidade de recomendar e adotar as medidas de prevenção e controle das doenças ou agravos.

Ainda com relação à vigilância em saúde, a LOS detalha uma proteção chamada especial, a proteção que envolve a saúde do trabalhador, determinando condições específicas de vigilância para a sua proteção. A vinculação da saúde do trabalhador com as ações da vigilância, especificamente, está disposta no parágrafo terceiro do art. 6:

Entende-se por saúde do trabalhador, para fins desta lei, um conjunto de atividades que se destina, através das ações de vigilância epidemiológica e vigilância sanitária, à promoção e proteção da saúde dos trabalhadores, assim como visa à recuperação e reabilitação da saúde dos trabalhadores submetidos aos riscos e agravos advindos das condições de trabalho.

Como o centro de nossa atenção diz respeito às ações da vigilância em saúde, especificamente da vigilância sanitária, é de fundamental relevância identificar, na lei, as competências legais de cada ente federativo. Entretanto, é imperioso identificar primeiramente as competências administrativas e legislativas em relação à saúde pública, nos termos da Constituição da República. É o que se passa a fazer.

\subsubsection{Competências legislativas e administrativas relacionadas à saúde pública}

$\mathrm{O}$ art. 23 da Carta Magna prevê a competência administrativa comum dos entes federativos no cuidado da saúde e assistência pública, bem como da proteção e garantia das pessoas portadoras de necessidades especiais. Ou seja, é dever da União, dos Estados, dos Municípios e do Distrito Federal cuidar concorrentemente da saúde pública, uma das áreas de maior importância para a sociedade e para o Estado (Pessoto et al., 2015) (Teixeira, 2002) (Jairnilson Silva Paim, 2018), sobretudo em tempos pandêmicos de COVID-19 (Santos \& Rocha Guimarães, 2020).

Portanto, todos os entes federativos devem concorrer para garantir a efetividade da saúde pública, de todas as ações e serviços de saúde, inclusive com relação à vigilância sanitária. Contudo, para se evitar conflitos federativos, a atuação comum deve estar pautada pelo princípio da predominância do interesse (S. G. Dallari, 1991) (De Moraes, 2009).

O art. 24 da Carta Magna prevê a competência legislativa em matéria de saúde pública (previdência social, proteção e defesa da sociedade - inciso XII), compartilhada entre a União, os Estados e o Distrito Federal. Adicionalmente, o art. 200, inciso I do mesmo diploma, define competir ao SUS, nos termos legais, além de outras atribuições, "controlar e fiscalizar procedimentos, produtos e substâncias de interesse para a saúde e participar da produção de medicamentos, equipamentos, imunobiológicos, hemoderivados e outros insumos", bem como "executar as ações de vigilância sanitária e epidemiológica", "fiscalizar e inspecionar alimentos, compreendido p controle de seu teor nutricional, bem como bebidas e águas para consumo humano".

A competência legislativa nesse caso é concorrente não-cumulativa ou vertical (Junior, 1995), uma vez que a União está limitada à criação de normas gerais, cabendo aos Estados e ao Distrito Federal esmiuçá-las a partir das suas respectivas leis, consoante o previsto no art. 24, parágrafo segundo da própria Constituição.

Caso haja inércia da União em disciplinar as matérias identificadas no art. 24, os Estados e o Distrito Federal poderão 
regulamentar a matéria, gozando tanto de competência plena para a confecção de normas gerais (como se União fossem) quanto normas de caráter específico. Contudo, caso a União queira exercer a sua competência editando lei federal, esta prevalecerá enquanto norma geral competente (suspendendo a eficácia da lei estadual/distrital no que lhe for contrário), o que nos permite afirmar que essa competência aqui listada ao Distrito Federal e aos Estado é temporária.

A competência dos entes municipais está prevista no art. 30 da Magna Carta brasileira, e compete a estes legislar sobre assuntos de interesse geral (inciso I), suplementar a legislação federal e estadual no que couber (inciso II), prestar, com a cooperação técnica e financeira da União e do Estado, serviços de atendimento à saúde da população (inciso VII). Essencial é apreender o "interesse local" como o elemento central dos assuntos de competência municipal, de onde deriva o princípio da predominância do interesse local.

É certo que muitas ações geram reflexos no interesse dos estados e da própria União, o que dificulta uma melhor caracterização do que pode ser entendido como "interesse local". Assim, salvo as hipóteses tradicionais e legais de interesse geral, as demais devem ser estudadas caso a caso, a fim de captar qual interesse é predominante naquele caso concreto (S. G. Dallari, 1991). O município pode, por exemplo, praticar atos legislativos com vistas a regulamentar a vigilância sanitária de alimentos de consumo imediato, inclusive com poder de polícia fiscalizador (Costa, 2009) (Piovesan \& et al, 2005) (Seta et al., 2006) (Lima, 2008).

Ou seja, pode o município suplementar a legislação federal e estadual, desde que presente o "interesse local", sendo-lhe vedada a contradição, inclusive nas matérias previstas no art. 24 da CF 88. E nos casos de serviços de saúde o interesse local está positivado na próprio Carta (inciso VII, como visto).

Portanto, todos os entes federativos são competentes (administrativamente) para tratar da Saúde Pública, inclusive de vigilância sanitária; e para dirimir os eventuais conflitos federativos, deve-se observar o princípio da predominância do interesse. Em relação à competência legislativa, cabe a União legislar sobre normas gerais, aos Estados e Distrito Federal legislar sobre normas específicas, e aos municípios a atuação fica mais restrita aos casos de existência de interesse local, consoante o princípio da predominância do interesse.

\subsubsection{Atribuições legais dos entes federativos com relação à vigilância sanitária}

A Lei Orgânica da Saúde (LOS) apresenta as competências/atribuições das esferas de governo com relação ao Sistema Único de Saúde (SUS), precisamente nos artigos 16 a 18. Dentre as múltiplas atribuições legais, como planejamento em saúde, recursos humanos, saúde do trabalhador, ciência e tecnologia, gestão, existe aquelas relacionadas à vigilância sanitária (Costa, 2009). É sobre elas que vamos nos deter nesta última seção do trabalho.

As responsabilidades da União no que concerne à vigilância estão previstas no art. 16. São elas: (i) definição e coordenação dos sistemas de vigilância (inciso III); (ii) estabelecimento de critérios, parâmetros e métodos para o controle da qualidade sanitária de produtos, substâncias e serviços de consumo e uso humanos (inciso VIII); (iii) controle e fiscalização de procedimentos, produtos e substâncias de interesse para a saúde (inciso XII); e (iv) execução das ações em circunstâncias especiais, como na ocorrência de agravos inusitados à saúde, que possam escapar do controle da direção estadual do SUS ou que representem risco de disseminação nacional (inciso XIX e parágrafo único).

As atribuições dos Estados federativos estão dispostas no art. 17 e destacamos as três mais relacionadas à vigilância: (i) coordenação, e em caráter complementar, execução de ações e serviços de vigilância sanitária (inciso IV, b); (ii) formulação de normas e estabelecimento de padrões, em caráter suplementar, de procedimentos de controle de qualidade para produtos e substâncias de consumo humano (inciso XII); e (iii) colaboração com a União na execução da vigilância sanitária de portos, aeroportos e fronteiras (inciso XIII).

Quanto aos Municípios, consoante o art. 18, compete a (i) execução de ações e serviços de vigilância sanitária, 
articulados com a direção estadual (inciso IV, b); e (ii) a colaboração com a União e os Estados na execução da vigilância sanitária de portos, aeroportos e fronteiras (inciso IX).

Por fim, o art. 19 prevê as competências do Distrito Federal, as quais englobam tanto as reservadas aos entes estaduais quanto as relacionadas aos municípios.

\section{Considerações Finais}

A partir dos estudos relacionados à "vigilância jurídica em saúde", foi possível perceber a centralidade do direito sanitário, compreendido como um direito coletivo e formando um campo autônomo, para a materialização do direito constitucional à saúde, uma vez que é fundamental o Estado estar munido de uma instrumentação jurídica robusta o suficiente para garantir esse direito constitucional, isto é, essa política pública.

Enfatizou-se, no estudo do direito sanitário, a vigilância em saúde (sanitária), por objetivar a redução dos riscos, doenças e agravos, entendida a partir do direito público à saúde, isto é, como um direito de todos e dever do Estado. Pela referida ênfase, buscou-se trazer a Lei n. 9782/1999, instituidora do Sistema Nacional de Vigilância Sanitária e a Lei Orgânica da Saúde (Lei n. 8080/1990), devido ao seu caráter vertebrador do sistema público de saúde.

Por fim, identificou-se que todos os entes federativos são competentes administrativa e legislativamente em matéria de saúde pública e de vigilância sanitária, sendo de crucial importância considerar o princípio da predominância do interesse, que, de certa forma, delineou a distribuição de atribuições constitucionais e infraconstitucionais em ambas as matérias.

Comparar o direito sanitário com outros ramos do direito, bem como investigar a história conceitual do "direito sanitário" são possibilidades sugestivas de trabalhos futuros, na medida em que oferecerão melhores subsídios teóricoconceituais a este ramo do direito, relativamente novo e cuja importância cresce paulatinamente.

\section{Referências}

Aith, F. M. A. (2006). Teoria geral do direito sanitário brasileiro [Doutorado em Serviços de Saúde Pública, Universidade de São Paulo]. https://doi.org/10.11606/T.6.2006.tde-23102006-144712

Aith, F. M. A. (2019). Manual de direito sanitário com enfoque em vigilância em saúde. CONASEMS.

Aith, F. M. A., Reis, R. R., Diaz-Quijano, F. A., Asano, C. L., \& Ventura, D. de F. L. (2020). Direitos na pandemia n. 01-Mapeamento e análise das normas jurídicas de resposta à Covid-19 no Brasil (Boletim de difusão científica Direitos na pandemia n. 01; Direitos na pandemia). CEPEDISA-USP/ Conectas Direitos Humanos. https://cepedisa.org.br/publicacoes/

Almeida Filho, N. de, \& Jucá, V. (2002). Saúde como ausência de doença: Crítica à teoria funcionalista de Christopher Boorse. Ciência \& Saúde Coletiva, 7(4), 879-889. https://doi.org/10.1590/S1413-81232002000400019

Baptista, T. W. de F., Machado, C. V., \& Lima, L. D. de. (2009). Responsabilidade do Estado e direito à saúde no Brasil: Um balanço da atuação dos Poderes. Ciência \& Saúde Coletiva, 14(3), 829-839. https://doi.org/10.1590/S1413-81232009000300018

Batistella, C. (2007). Saúde, doença e cuidado: Complexidade teórica e necessidade histórica. In O território e o processo saúde-doença (p. 265).

Berlinguer, G. (1978). Medicina e política. Hucitec.

Birman, J. (2005). A Physis da saúde coletiva. Physis: Revista de Saúde Coletiva, 15(suppl), 11-16. https://doi.org/10.1590/S0103-73312005000000002

Bonavides, P. (2019). Curso de Direito Constitucional (34 $\left.{ }^{\mathrm{a}} \mathrm{ed}\right)$. Malheiros.

Buss, P. M., Machado, J. M. H., Gallo, E., Magalhães, D. de P., Setti, A. F. F., Franco Netto, F. de A., \& Buss, D. F. (2012). Governança em saúde e ambiente para o desenvolvimento sustentável. Ciência \& Saúde Coletiva, 17(6), 1479-1491. https://doi.org/10.1590/S1413-81232012000600012

Campos, G. W. de S. (2000). Saúde pública e saúde coletiva: Campo e núcleo de saberes e práticas. Ciência \& Saúde Coletiva, 5(2), 219-230. https://doi.org/10.1590/S1413-81232000000200002

Campos, G. W. de S. (2006). Reflexões temáticas sobre eqüidade e saúde: O caso do SUS. Saúde e Sociedade, 15(2), 23-33. https://doi.org/10.1590/S010412902006000200004

Castro, E. B. V. de. (1992). From the enemy's point of view: Humanity and divinity in an Amazonian society. University of Chicago Press. 
Cittadino, G. (2002). Judicialização da política, constitucionalismo democrático e separação de poderes. In A democracia e os três poderes no Brasil (p. 17-42). UFMG e IUPERJ/FAPERJ.

Costa, E. A. (2009). Vigilância sanitária: Temas para debate. EDUFBA. http://books.scielo.org/id/6bmrk

Cotrim Junior, D. F. (2019). Resistências Institucionalizadas: Gênese e lutas do Movimento sanitário brasileiro [Mestrado em Ciências Jurídicas, Pontifícia Universidade Católica do Rio de Janeiro]. https://doi.org/10.17771/PUCRio.acad.46209

Cotrim Junior, D. F., \& Cabral, L. M. da S. (2020). Ações do Governo Federal no combate à coronacrise: Limites, insuficiências e escassos acertos. Physis: Revista de Saúde Coletiva, 30(2), e300225. https://doi.org/10.1590/s0103-73312020300225

Cotrim Junior, D. F., Cabral, L. M. da S., \& Asensi, F. D. (2021). Oferta de leitos de UTI no Brasil à luz dos princípios constitucionais da Igualdade e da Universalidade em tempos de COVID-19. Direito Público, 17(96). https://www.portaldeperiodicos.idp.edu.br/direitopublico/article/view/4554

Cotrim Junior, D. F., Cabral, L. M. da S., \& Machado, F. R. de S. (2020). Fila única de leitos: Urgência, dificuldades e enfrentamentos. P2P E INOVAÇÃO, 7, 212-229. https://doi.org/10.21721/p2p.2020v7n1.p212-229

Dallari, S. (2013). Aspectos particulares da chamada judicialização da saúde. Revista de Direito Sanitário, 14(1), 77. https://doi.org/10.11606/issn.23169044.v14i1p77-81

Dallari, S. G. (1988). Uma nova disciplina: O direito sanitário. Revista de Saúde Pública, 22(4), 327-334. https://doi.org/10.1590/S0034-89101988000400008

Dallari, S. G. (1991). O papel do município no desenvolvimento de políticas de saúde. Revista de saúde pública, 25, 401-405.

Dallari, S. G. (2002). Direito Sanitário. Revista Direito e Democracia (Canoas), 3(1), 07-41.

De Moraes, A. (2009). Federação brasileira-necessidade de fortalecimento das competências dos estados-membros. Revista de Direito Administrativo, 251, 1127 .

De Seta, M. H. (2007). A construção do Sistema Nacional de Vigilância Sanitária: Uma análise das relações intergovernamentais na perspectiva do federalismo [Tese de Doutorado em Saúde Coletiva]. Universidade do Estado do Rio de Janeiro.

De Seta, M. H., \& Dain, S. (2010). Construção do Sistema Brasileiro de Vigilância Sanitária: Argumentos para debate. Ciência \& Saúde Coletiva, 15(suppl 3), 3307-3317. https://doi.org/10.1590/S1413-81232010000900002

Di Pietro, M. S. Z. (2017). Direito Administrativo (30a ed). Forense.

Donnangelo, M. C. F. (1976). Saúde e Sociedade. Duas Cidades.

Escorel, S. (1999). Reviravolta na saúde: Origem e Articulação Do Movimento Sanitário. Editora FIOCRUZ. Fundação Oswaldo Cruz SciELO. http://books.scielo.org/id/qxhc3

Fleury, S., Ouverney, A. L. M., Kronemberger, T. S., \& Zani, F. B. (2011). Governança local no sistema descentralizado de saúde no Brasil. Revista Panamericana de Salud Pública (Impresa) / Pan American Journal of Public Health (Impresa), 28, 446-455.

Garcia, F. de B. S., Ruviaro, D., Semzezem, P., \& Toretta, E. T. (2020). A contradição entre o Estado e a garantia de direitos no atual contexto de crise do capitalismo. Research, Society and Development, 9(10), e1179108325. https://doi.org/10.33448/rsd-v9i10.8325

Germain, G., Simon, A., Arsenault, J., Baron, G., Bouchard, C., Chaumont, D., Allaki, F. E., Kimpton, A., Lévesque, B., Massé, A., Mercier, M., Ogden, N., Picard, I., Ravel, A., Rocheleau, J., \& Soto, J. (2019). Quebec's Multi-Party Observatory on Zoonoses and Adaptation to Climate Change. Canada Communicable Disease Report, 45(5), 143-148. https://doi.org/10.14745/ccdr.v45i05a05

Gil, A. C. (2009). Como elaborar projetos de pesquisa. Atlas.

Gomes, C. B., \& Gonzaga e Castro, L. de P. (2012). O novo Regulamento Sanitário Internacional. Revista de Direito Sanitário, 13(2), 137. https://doi.org/10.11606/issn.2316-9044.v13i2p137-155

Herrero, M., \& Thornton, P. (2020). What can COVID-19 teach us about responding to climate change? The Lancet Planetary Health, 4(5), e174. https://doi.org/10.1016/S2542-5196(20)30085-1

Junior, T. S. F. (1995). Normas gerais e competência concorrente. Uma exegese do art. 24 da Constituição Federal. Revista da Faculdade de Direito, Universidade de São Paulo, 90, 245-251.

Köche, J. C. (2011). Fundamentos de metodologia científica: Teoria da ciência e iniciação à pesquisa. Vozes.

Lara, M., Fernandes, C. M. da S., Penteado, V. P., \& Serra, M. da C. (2021). Direito à saúde e judicialização no acesso a tratamentos de média e alta complexidade pelo Sistema Único de Saúde (SUS). Research, Society and Development, 10(3), e16010313091. https://doi.org/10.33448/rsd-v10i3.13091

Latour, B. (1991). Jamais fomos modernos: Ensaio de antropologia simetrica.

Lima, Y. O. R. (2008). Trabalho em saúde: O poder de polícia na visão do professional de vigilância sanitária. [Instituto de Saúde Coletiva. Universidade Federal da Bahia]. http://www.repositorio.ufba.br/ri/handle/ri/10893

Luz, M. T. (2014). Instituições Médicas no Brasil. Editora da Rede Unida.

Machado, F. R. de S. (2006). Direito à saúde, integralidade e participação: Um estudo sobre as relações entre Sociedade e Ministério Público na experiência de Porto Alegre [Dissertação]. Universidade do Estado do Rio de Janeiro. 
Machado, F. R. de S. (2008). Contribuições ao debate da judicialização da saúde no Brasil. Revista de Direito Sanitário, 9(2), 73. https://doi.org/10.11606/issn.2316-9044.v9i2p73-91

Machado, F. R. de S. (2009). O direito à saúde na interface entre sociedade civil e Estado. Trabalho, Educação e Saúde, 7(2), 355-371. https://doi.org/10.1590/S1981-77462009000200009

Machado, F. R. de S., \& Dain, S. (2012). A Audiência Pública da Saúde: Questões para a judicialização e para a gestão de saúde no Brasil. Revista de Administração Pública, 46(4), 1017-1036. https://doi.org/10.1590/S0034-76122012000400006

Manzanedo, R. D., \& Manning, P. (2020). COVID-19: Lessons for the climate change emergency. Science of The Total Environment, 742, 140563. https://doi.org/10.1016/j.scitotenv.2020.140563

Oliveira, E. A. de. (2020). Estado e direito no capitalismo: Um debate entre o liberalismo e marxismo. Revista Katálysis, 23(2), 213-222. https://doi.org/10.1590/1982-02592020v23n2p213

Oliveira, J. B. F. de, Tavares, E. M. F., \& Costa, J. B. A. da. (2021). Políticas públicas, economicidade e judicialização da saúde. Research, Society and Development, 10(4), e37410414331. https://doi.org/10.33448/rsd-v10i4.14331

Ortega, F., \& Orsini, M. (2020). Governing COVID-19 without government in Brazil: Ignorance, neoliberal authoritarianism, and the collapse of public health leadership. Global Public Health, 15(9), 1257-1277. https://doi.org/10.1080/17441692.2020.1795223

Paim, Jairnilson S., \& Almeida Filho, N. de. (1998). Saúde coletiva: Uma "nova saúde pública" ou campo aberto a novos paradigmas? Revista de Saúde Pública, 32(4), 299-316. https://doi.org/10.1590/S0034-89101998000400001

Paim, Jairnilson Silva. (2008). Reforma sanitária brasileira: Contribuição para a compreensão e crítica. EDUFBA; Editora Fiocruz.

Paim, Jairnilson Silva. (2018). Sistema Único de Saúde (SUS) aos 30 anos. Ciência \& Saúde Coletiva, 23(6), 1723-1728. https://doi.org/10.1590/141381232018236.09172018

Paim, Jairnilson Silva, \& Silva, L. M. V. (2010). Universalidade, integralidade, equidade e SUS. BIS. Boletim do Instituto de Saúde (Impresso), 12(2). http://periodicos.ses.sp.bvs.br/scielo.php?script=sci_abstract\&pid=S1518-18122010000200002\&lng=pt\&nrm=iso\&tlng=pt

Pessoto, U. C., Ribeiro, E. A. W., \& Guimarães, R. B. (2015). O papel do Estado nas políticas públicas de saúde: Um panorama sobre o debate do conceito de Estado e caso brasileiro. Saúde e Sociedade, 24(1), 9-22. https://doi.org/10.1590/S0104-12902015000100001

Piovesan, M. F., \& et al. (2005). PIOVESAN, Márcia Franke et al. Vigilância Sanitária: Uma proposta de análise dos contextos locais. Revista Brasileira de Epidemiologia, v. 8, p. 83-95, 2005. Revista Brasileira de Epidemiologia, 8, 83-95.

Santos, R. T. dos, Cotrim Junior, D. F., Cabral, L. M. da S., Franco, T. de A. V., Pitthan, R. G. V., \& Gomes, B. C. (2021). Saúde Pública e Comunicação: Impasses do SUS à luz da formação democrática da opinião pública. Ciência \& Saúde Coletiva, Ahead of Print. http://cienciaesaudecoletiva.com.br/artigos/saude-publica-e-comunicacao-impasses-do-sus-a-luz-da-formacao-democratica-da-opiniao-publica/18054

Santos, R. T. dos, \& Rocha Guimarães, J. (2020). Democracia sem sentimento de república: O SUS nos tempos da COVID-19 [Preprint]. https://doi.org/10.1590/SciELOPreprints.1271

Santos, L., \& Andrade, L. O. M. de. (2012). Acesso às ações e aos serviços de saúde: Uma visão polissêmica. Ciência \& Saúde Coletiva, 17(11), 2876-2878. https://doi.org/10.1590/S1413-81232012001100003

Santos, R. T. D. (2020). O neoliberalismo como linguagem política da pandemia: A Saúde Coletiva e a resposta aos impactos sociais. Physis: Revista de Saúde Coletiva, 30(2), e300211. https://doi.org/10.1590/s0103-73312020300211

Scliar, M. (2007). História do conceito de saúde. Physis: Revista de Saúde Coletiva, 17(1), 29-41. https://doi.org/10.1590/S0103-73312007000100003

Segre, M., \& Ferraz, F. C. (1997). O conceito de saúde. Revista de Saúde Pública, 31(5), 538-542. https://doi.org/10.1590/S0034-89101997000600016

Seta, M. H. D., Oliveira, C. V. dos S., \& Pepe, V. L. E. (2017). Proteção à saúde no Brasil: O Sistema Nacional de Vigilância Sanitária. Ciência \& Saúde Coletiva, 22(10), 3225-3234. https://doi.org/10.1590/1413-812320172210.16672017

Seta, M. H. D., Pepe, V. L. E., \& Oliveira, G. O. de. (2006). Gestão e vigilância sanitária: Modos atuais do pensar e fazer. SCIELO EDITORA FIOCRUZ. http://www.jstor.org/stable/10.7476/9788575413265

Silva, J. A. A. da, Costa, E. A., \& Lucchese, G. (2018). SUS 30 anos: Vigilância Sanitária. Ciência \& Saúde Coletiva, 23(6), 1953-1961. https://doi.org/10.1590/1413-81232018236.04972018

Tavares, L. P., Oliveira Júnior, F. L. de, \& Magalhães, M. (2020). Análise dos discursos do Presidente Jair Bolsonaro em meio à pandemia: O coronavírus é só uma "gripezinha"? Research, Society and Development, 9(7), e609974469. https://doi.org/10.33448/rsd-v9i7.4469

Teixeira, E. C. (2002). O papel das políticas públicas no desenvolvimento local e na transformação da realidade. Salvador, AATR.

Temporão, J. G. (2003). O Programa Nacional de Imunizações (PNI): Origens e desenvolvimento. História, Ciências, Saúde-Manguinhos, 10(suppl 2), 601617. https://doi.org/10.1590/S0104-59702003000500008

Ventura, M., Simas, L., Pepe, V. L. E., \& Schramm, F. R. (2010). Judicialização da saúde, acesso à justiça e a efetividade do direito à saúde. Physis: Revista de Saúde Coletiva, 20(1), 77-100. https://doi.org/10.1590/S0103-73312010000100006 
Research, Society and Development, v. 10, n. 6, e14410615483, 2021

(CC BY 4.0) | ISSN 2525-3409 | DOI: http://dx.doi.org/10.33448/rsd-v10i6.15483

Watts, N., Amann, M., Ayeb-Karlsson, S., Belesova, K., Bouley, T., Boykoff, M., Byass, P., Cai, W., Campbell-Lendrum, D., Chambers, J., Cox, P. M., Daly, M., Dasandi, N., Davies, M., Depledge, M., Depoux, A., Dominguez-Salas, P., Drummond, P., Ekins, P., ... Costello, A. (2018). The Lancet Countdown on health and climate change: From 25 years of inaction to a global transformation for public health. The Lancet, 391(10120), 581-630. https://doi.org/10.1016/S0140-6736(17)32464-9 